\title{
Situação epidemiológica da brucelose bovina no Estado do Rio Grande do Sul
}

\author{
[Epidemiological situation of bovine brucellosis in the State of Rio Grande do Sul, Brazil]
}

\author{
M.F.V. Marvulo ${ }^{1}$, F. Ferreira ${ }^{1}$, R.A. Dias ${ }^{1}$, M. Amaku ${ }^{1}$, A.C.M. Groff ${ }^{2}$, V.S.P. Gonçalves ${ }^{3}$, \\ V.C.F. Figueiredo ${ }^{4}$, J.R. Lôbo $^{4}$, J.S. Ferreira Neto ${ }^{1 *}$ \\ ${ }^{1}$ Faculdade de Medicina Veterinária e Zootecnia - USP \\ Av. Prof. Dr. Orlando Marques de Paiva, 87 \\ 05508-270 - São Paulo, SP \\ ${ }^{2}$ Secretaria da Agricultura, Pecuária, Pesca e Agronegócio do Estado do Rio Grande do Sul - Porto Alegre, RS \\ ${ }^{3}$ Faculdade de Agronomia e Medicina Veterinária - UnB - Brasília, DF \\ ${ }^{4}$ Departamento de Saúde Animal - SDA-MAPA - Brasília, DF
}

\begin{abstract}
RESUMO
Realizou-se um estudo para caracterizar a situação epidemiológica da brucelose bovina. O Estado foi dividido em sete regiões. Em cada região foram amostradas aleatoriamente cerca de 300 propriedades, e dentro dessas foi escolhido de forma aleatória um número pré-estabelecido de animais, dos quais foi obtida uma amostra de sangue. No total foram amostrados 16.072 animais, provenientes de 1.957 propriedades. Em cada propriedade amostrada foi aplicado um questionário epidemiológico para verificar o tipo de exploração e as práticas zootécnicas e sanitárias que poderiam estar associadas ao risco de infecção pela doença. O protocolo de testes utilizado foi o da triagem com o teste do antígeno acidificado tamponado e o reteste dos positivos com o teste do 2-mercaptoetanol. O rebanho foi considerado positivo se pelo menos um animal foi reagente às duas provas sorológicas. Para o Estado, as prevalências de focos e de animais infectados foram, respectivamente, $2,1 \%$ [1,5-2,6\%] e 1,0\% [0,60-1,4\%]. Para os circuitos, a prevalência de focos e a de animais foram, respectivamente: circuito $1,3,1 \%[1,4-5,7 \%]$ e $0,95 \%[0,0$ $2,0 \%]$; circuito $2,7,7 \%$ [4,9-11,3\%] e $1,0 \%$ [0,40-1,7\%]; circuito $3,5,7 \%$ [3,4-8,8\%] e $2,1 \%[0,41-$ $3,8 \%]$; circuito $4,0,66 \%[0,08-2,4 \%]$ e $0,66 \%[0,0-1,8 \%]$; circuito $5,0,66 \%[0,08-2,4 \%]$ e $0,05 \%[0,0-$ $0,13 \%]$; circuito $6,0,0 \%[0,0-1,3 \%]$ e $0,0 \%[0,0-0,25 \%]$; circuito $7,5,4 \%[2,5-10,1 \%]$ e $2,9 \%[0,49-$ $5,3 \%]$. Os fatores de risco (odds ratio, OR) associados à condição de foco foram: exploração de corte $(\mathrm{OR}=4,27[1,82-10,01])$ e histórico de aborto $(\mathrm{OR}=3,27,[1,71-6,25])$.
\end{abstract}

Palavras-chave: bovino, brucelose, prevalência, fatores de risco, Rio Grande do Sul

\begin{abstract}
A study to characterize the epidemiological status of bovine brucellosis was carried out in the State of Rio Grande do Sul. The State was divided in seven regions. Three hundred herds were randomly sampled in each region and a pre-established number of animals were sampled in each of these herds. A total of 16,072 serum samples from 1,957 herds, were collected. In each herd, it was applied an epidemiological questionnaire focused on herd traits as well as husbandry and sanitary practices that could be associated with the risk of infection. The serum samples were screened for antibodies against Brucella spp. by the Rose-Bengal Test and all positive sera were re-tested by the 2-mercaptoethanol test. The herd was considered positive if at least one animal was positive on both tests. The prevalences of infected herds and animals in the State were, respectively 2.1\% [1.5-2.6\%] and 1.0\% [0.60-1.4\%]. In the regions, the prevalences of infected herds and animals were, respectively: region 1, 3.1\% [1.4-5.7\%] and $0.95 \%$ [0.0-2.0\%]; region 2, 7.7\% [4.9-11.3\%] and 1.0\% [0.40-1.7\%]; region 3, 5.7\% [3.4-8.8\%] and 2.1\% [0.41-3.8\%]; region 4, $0.66 \%$ [0.08-2.4\%] and 0.66\% [0.0-1.8\%]; region 5, $0.66 \%$ [0.08-2.4\%] and
\end{abstract}

Recebido em 27 de março de 2009

Aceito em 23 de setembro de 2009

*Autor para correspondência (corresponding author)

E-mail: jsoares@vps.fmvz.usp.br 
$0.05 \%$ [0.0-0.13\%]; region 6, $0.0 \%$ [0.0-1.3\%] and $0.0 \%$ [0.0-0.25\%]; and region 7, 5.4\% [2.5-10.1\%] and $2.9 \%[0.49-5.3 \%]$. The risk factors (odds ratio, OR) associated with the presence of infection were: beef herd $(O R=4.27[1.82-10.01])$ and recent history of abortion $(O R=3.27-1.71-6.25])$.

\section{Keywords: cattle, brucellosis, prevalence, risk factors, Rio Grande do Sul, Brazil}

\section{INTRODUÇÃO}

O Estado do Rio Grande do Sul (RS) está localizado na região Sul do Brasil, formando parte da Bacia do Rio da Prata, com uma área geográfica de $260.000 \mathrm{~km}^{2}$. A área pecuária é de grande importância (Dutra, 2003), com 11.148.126 bovinos e 50.976 bubalinos (IBGE, 2006), distribuídos em 398.216 propriedades (Groff, 2007; SEAPPA-RS; comunicação pessoal), sendo $45 \%$ de seu produto interno bruto (PIB) vinculado ao agronegócio. De acordo com o IBGE (2006), o RS possui $6,6 \%$ do efetivo bovino do País e é responsável por $12,8 \%$ do total de leite bovino produzido.

A vocação pecuária do Estado teve início no século XVII. Relatos indicam que os bovinos foram introduzidos pelos jesuítas por volta do ano de 1626. A população de bovinos do RS é composta principalmente por raças européias como Hereford, Angus, Devon e Charolês, que encontraram condições favoráveis para seu desenvolvimento devido ao clima semelhante ao dos países de origem, temperado, com estações definidas e pastagens de boa qualidade (Silva, 1947; Richter, 1971; Avila, 1973; Domingues, 1982). Os bovinos são criados principalmente de maneira extensiva em pastagem natural (Richter, 1971; Avila, 1973).

Com base nas características geográficas, sociais e econômicas, o RS foi dividido em sete mesorregiões. O serviço veterinário oficial do Estado compreende 251 Unidades Locais do Departamento de Produção Animal (DPA) da Secretaria da Agricultura, Pecuária, Pesca e Agronegócio, que desenvolvem ações sanitárias nos seus 496 municípios. Os municípios com os maiores rebanhos de bovinos encontram-se na metade sul do Estado. Nessa região concentramse $65 \%$ do total de bovídeos do Estado, criados de forma extensiva e destinados preferencialmente à produção de carne. No norte do Estado encontra-se o maior número de propriedades, porém pequenas e principalmente dedicadas à produção de leite (Santos et al., 2007).
Em 1936, Desidério Finamor detectou pela primeira vez bovinos soropositivos para brucelose no Rio Grande do Sul e propôs um plano para o seu controle (Paulin e Ferreira Neto, 2003). As iniciativas de combate à brucelose bovina no Estado foram pioneiras no Brasil. Em 1941, foram promulgados os decretos-leis estaduais números 276 e 276a, que regulamentavam a entrada de reprodutores importados e a admissão de animais em exposições e feiras com resultados negativos para brucelose. Em 1948, o Centro de Pesquisas Desidério Finamor foi encarregado da produção da vacina B19, que era aplicada nos animais pelas Inspetorias Veterinárias dos municípios (Rio Grande do Sul, 1961). Em 1953, criou-se o Serviço de Erradicação da Brucelose Bovina e foram organizados planos de controle baseados no programa americano. $\mathrm{O}$ resultado não foi satisfatório devido à produção insuficiente de vacina pelo Estado. Em 1961, outro programa foi iniciado, baseado na vacinação de bezerras entre quatro e oito meses de idade, na realização de sorodiagnóstico em todos os plantéis e na marcação dos vacinados e dos reagentes. Em 1964, a Lei Estadual número 4890 instituiu a obrigatoriedade do combate à brucelose animal. O Decreto Lei $\mathrm{n}^{\circ} 17217$, publicado em 1965 , aprovou o regulamento do serviço de combate à brucelose animal e tornou obrigatória a vacinação das bezerras entre quatro e oito meses de idade.

A partir da década de 50 foram realizados diversos estudos sorológicos para o diagnóstico da brucelose no Brasil. Em 1951, Caldas e Ribeiro detectaram uma frequência de $8,2 \%$ de bovinos soropositivos no Estado do Rio Grande do Sul (Paulin e Ferreira Neto, 2003). Em 1975, o Ministério da Agricultura (MA) realizou o primeiro inquérito sorológico nacional e a prevalência nos animais no RS foi de 2,0\% (Almeida et al., 1988). Em 1986, em outro estudo realizado pelo MA no RS, a prevalência havia caído para $0,3 \%$ (Paulin e Ferreira Neto, 2003). Essa diminuição da prevalência provavelmente foi resultado do programa de vacinação no Estado e do melhor controle da 
doença pelos criadores de gado de leite (Boletim..., 1998-2000; Poester et al., 2002). Entre 1995 e 1998, dados publicados no Boletim de Defesa Sanitária Animal relataram frequências de focos que variavam entre $0,42 \% \mathrm{e}$ $1,35 \%$ e frequências de animais soropositivos variando entre $0,03 \%$ e $1,0 \%$ (Boletim..., 19982000).

Entre janeiro de 1996 e agosto de 2007, os exames sorológicos de rotina no Estado totalizaram 507.924 bovinos e bubalinos, com $0,73 \%$ de animais positivos para brucelose (Groff, 2007; SEAPPA-RS; comunicação pessoal). Embora esses dados não sejam provenientes de uma amostra planejada, representam uma fonte importante e regular de informações.

O Estado do Rio Grande do Sul foi um dos primeiros a realizar estudos de prevalência e de controle da brucelose no País. Ainda assim, a doença não está adequadamente caracterizada em todo Estado. Desse modo, este estudo teve por objetivos estimar a prevalência e identificar os fatores de risco para a brucelose bovina no Estado, e fornecer subsídios para a melhor implementação e gestão do Programa Nacional de Controle e Erradicação da Brucelose e Tuberculose (PNCEBT).

\section{MATERIAL E MÉTODOS}

O estudo foi planejado por técnicos do Ministério da Agricultura, Pecuária e Abastecimento, da Universidade de São Paulo e da Universidade de Brasília, em colaboração com os técnicos da Divisão de Fiscalização e Defesa Sanitária Animal (DFDSA), Departamento de Produção Animal (DPA) da Secretaria da Agricultura, Pecuária, Pesca e Agronegócio (SEAPPA), RS. O trabalho de campo foi realizado por técnicos da DFDSA/DPA/SEAPPA-RS, no período de novembro a dezembro de 2004.

Para o conhecimento das diferenças regionais nos parâmetros epidemiológicos da brucelose bovina, o Estado do Rio Grande do Sul foi dividido em sete circuitos produtores de bovinos, levando-se em consideração os diferentes sistemas de produção, práticas de manejo, finalidades de exploração, tamanho médio de rebanhos e sistemas de comercialização. A divisão do Estado em regiões correspondentes a circuitos produtores também levou em conta a capacidade operacional e logística do serviço veterinário oficial do Estado para a realização das atividades de campo, baseando-se nas áreas de atuação das suas unidades regionais.

Em cada circuito produtor, estimou-se a prevalência de propriedades infectadas pela brucelose bovina e a de animais soropositivos por meio de um estudo amostral em dois estágios, dirigido para detectar focos da doença. No primeiro estágio, sorteou-se, aleatoriamente, um número pré-estabelecido de propriedades com atividade reprodutiva (unidades primárias de amostragem). No segundo, sorteou-se um número pré-estabelecido de fêmeas bovinas com idade igual ou superior a 24 meses (unidades secundárias de amostragem).

Nas propriedades rurais onde existia mais de um rebanho, foi escolhido o rebanho bovino de maior importância econômica, no qual os animais estavam submetidos ao mesmo manejo, ou seja, sob os mesmos fatores de risco. A escolha da unidade primária de amostragem foi aleatória, baseada no cadastro de propriedades rurais com atividade reprodutiva de bovinos. A propriedade sorteada que, por motivos vários, não pôde ser visitada, foi substituída por outra, nas proximidades e com as mesmas características de produção. $\mathrm{O}$ número de propriedades selecionadas por circuito foi estimado pela fórmula para amostras simples aleatórias (Thrusfield, 2007). Os parâmetros adotados para o cálculo foram: nível de confiança de 0,95 , prevalência estimada de 0,25 e erro de 0,05. A capacidade operacional e financeira do serviço veterinário oficial do Estado também foi levada em consideração para a determinação do tamanho da amostra por circuito.

O planejamento amostral para as unidades secundárias visou estimar um número mínimo de animais a serem examinados dentro de cada propriedade de forma a permitir a sua classificação como foco ou não foco de brucelose. Para tanto, foi utilizado o conceito de sensibilidade e especificidade agregadas (Dohoo et al., 2003). Para efeito dos cálculos foram adotados os valores de $95 \%$ e $99,5 \%$, respectivamente, para a sensibilidade e a especificidade do protocolo de testes utilizado 
(Fletcher et al., 1998) e 20\% para a prevalência estimada. Nesse processo foi utilizado o programa Herdacc versão 3 , e o tamanho da amostra escolhido foi aquele que permitiu valores de sensibilidade e especificidade de rebanho iguais ou superiores a $90 \%$. Assim, nas propriedades com até 99 fêmeas com idade superior a 24 meses, foram amostrados 10 animais e nas com 100 ou mais fêmeas com idade superior a 24 meses, 15 animais. A escolha das fêmeas dentro das propriedades foi casual sistemática.

O protocolo do sorodiagnóstico foi composto pela triagem com o teste do antígeno acidificado tamponado (Rosa Bengala), seguida do reteste dos positivos com o teste do 2-mercaptoetanol, de acordo com as recomendações do PNCEBT (Brasil, 2006). O sangue foi coletado por punção da veia jugular com agulha descartável estéril em tubo com vácuo, previamente identificado. Os soros, armazenados em microtubos de plástico, foram mantidos a $-20^{\circ} \mathrm{C}$ até a realização dos testes. Os testes sorológicos foram realizados no Instituto de Pesquisas Veterinárias Desidério Finamor (IPVDF), em Eldorado do Sul, RS.

A propriedade foi considerada positiva quando se detectou pelo menos um animal positivo. As propriedades que apresentaram animais com resultado sorológico inconclusivo, sem nenhum positivo, foram classificadas como suspeitas e excluídas das análises. $\mathrm{O}$ mesmo tratamento foi dado aos animais com resultados sorológicos inconclusivos.

O planejamento amostral permitiu determinar as prevalências de focos e de fêmeas adultas $(\geq 24 \mathrm{~m})$ soropositivas para brucelose no Estado e também nos circuitos produtores. Os cálculos das prevalências aparentes e os respectivos intervalos de confiança foram realizados conforme preconizado por Dean et al. (1994). Os cálculos das prevalências de focos e de animais no Estado, e de prevalências de animais dentro das regiões foram feitos de forma ponderada (Dohoo et al., 2003).

O peso de cada propriedade no cálculo da prevalência de focos no Estado foi dado por

$$
P_{1}=\frac{\text { propriedades na região }}{\text { propriedades amostradas na região }}
$$

O peso de cada animal no cálculo da prevalência de animais no Estado foi dado por

$$
P_{2}=\frac{\text { fêmeas } \geq 24 \text { meses na propriedade }}{\text { fêmeas } \geq 24 \text { meses amostradas na propriedade }} \times \frac{\text { fêmeas } \geq 24 \text { meses na região }}{\text { fêmeas } \geq 24 \text { meses nas propriedades amostradas na região }}
$$

$\mathrm{Na}$ expressão acima, o primeiro termo refere-se ao peso de cada animal no cálculo das prevalências de animais dentro das regiões.

Em cada propriedade amostrada, além da coleta de sangue para a sorologia, foi também aplicado um questionário epidemiológico, elaborado para obter informações sobre o tipo de exploração e as práticas de manejo empregadas.

As variáveis analisadas foram: tipo ou sistema de exploração (carne, leite e misto), tipo de criação (confinado, semiconfinado, extensivo), uso de inseminação artificial, raças predominantes, número de vacas com idade superior a 24 meses, número de bovinos na propriedade, presença de outras espécies domésticas, presença de animais silvestres, destino da placenta e dos fetos abortados, compra e venda de animais, vacinação contra brucelose, abate de animais na propriedade, aluguel de pastos, pastos comuns com outras propriedades, pastos alagados, piquete de parição e assistência veterinária.

As variáveis foram organizadas de modo a apresentarem-se em escala crescente de risco. Quando necessário, realizou-se a recategorização das variáveis. A categoria de menor risco foi considerada como base para a comparação das demais categorias. As variáveis quantitativas foram categorizadas em percentis.

Foi feita uma primeira análise exploratória dos dados (univariada) para seleção daquelas com $\mathrm{p} \leq 0,20$ para o teste do $\chi^{2}$ ou exato de Fisher e, subsequente, oferecimento dessas à regressão logística. Os cálculos foram realizados com o auxílio do programa SPSS, versão 9.0. 
Todas as informações geradas pelo trabalho de campo e de laboratório foram inseridas em um banco de dados específico, utilizado nas análises epidemiológicas.

\section{RESULTADOS E DISCUSSÃO}

O Estado foi dividido em sete diferentes circuitos, considerando as características regionais da produção pecuária (Fig. 1). $\mathrm{Na}$ Tab. 1, apresentam-se os dados censitários do Estado e da amostra, segundo o circuito produtor.

Para o Estado, a mediana de fêmeas com idade igual ou superior a 24 meses foi de 57 para as propriedades de corte, 9 para as de leite e 5 para as mistas.

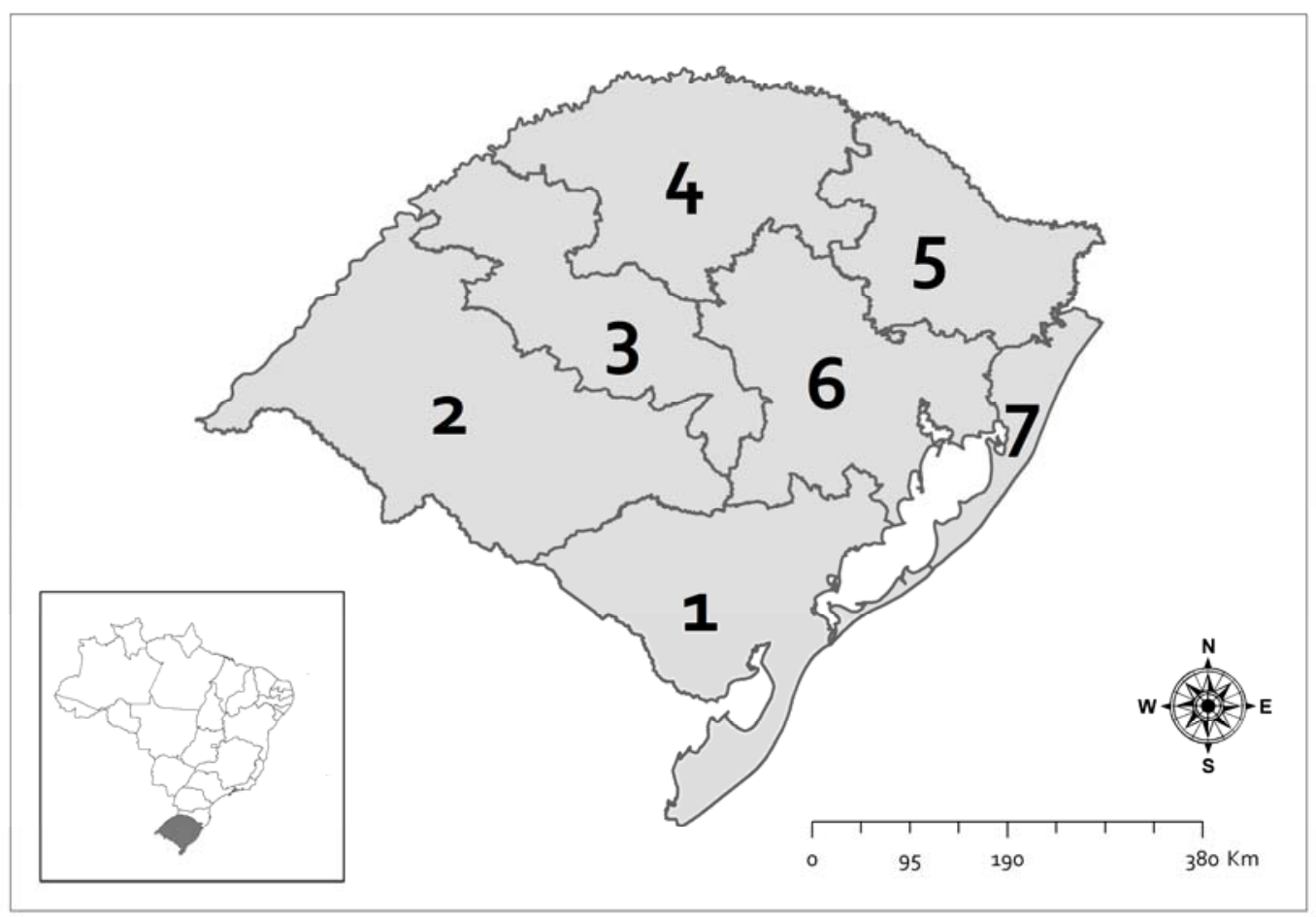

Figura 1. Mapa do Estado do Rio Grande do Sul com a divisão em circuitos produtores. No detalhe, a localização do Estado do Rio Grande do Sul no Brasil.

Tabela 1. Dados censitários da população bovina do Estado do Rio Grande do Sul em 2004, segundo o circuito produtor

\begin{tabular}{|c|c|c|c|c|c|}
\hline Circuito produtor & Núcleos regionais & $\begin{array}{c}\text { Total de } \\
\text { propriedades com } \\
\text { atividade } \\
\text { reprodutiva } \\
\end{array}$ & $\begin{array}{l}\text { Propriedades } \\
\text { amostradas }\end{array}$ & $\begin{array}{c}\text { Total de } \\
\text { fêmeas com } \\
\text { idade } \geq 24 \\
\text { meses } \\
\end{array}$ & $\begin{array}{c}\text { Fêmeas } \\
\text { amostradas }\end{array}$ \\
\hline 1- Sul & Bagé, Pelotas & 34.908 & 294 & 1.046 .003 & 2.396 \\
\hline 2- Fronteira Oeste & Alegrete, Uruguaiana & 30.318 & 298 & 2.219 .933 & 3.626 \\
\hline 3- Missões Central & $\begin{array}{l}\text { Santa Maria, São Luiz } \\
\text { Gonzaga }\end{array}$ & 51.729 & 318 & 957.908 & 3.736 \\
\hline 4- Norte & $\begin{array}{l}\text { Cruz Alta, Erechim, Ijui, } \\
\text { Palmeira das Missões, } \\
\text { Passo Fundo, Santa Rosa }\end{array}$ & 139.501 & 302 & 697.219 & 1.991 \\
\hline 5- Serra & $\begin{array}{l}\text { Caxias do Sul, Lagoa } \\
\text { Vermelha, }\end{array}$ & 39.295 & 300 & 486.090 & 1.919 \\
\hline 6- Metropolitana & $\begin{array}{l}\text { Estrela, Porto Alegre, Rio } \\
\text { Pardo, Soledade }\end{array}$ & 86.074 & 280 & 692.043 & 1.471 \\
\hline $\begin{array}{l}\text { 7- Litoral Norte } \\
\text { Total }\end{array}$ & Osório & $\begin{array}{c}11.162 \\
392.987\end{array}$ & $\begin{array}{c}165 \\
1.957\end{array}$ & $\begin{array}{c}214.213 \\
6.313 .409\end{array}$ & $\begin{array}{c}933 \\
16.072\end{array}$ \\
\hline
\end{tabular}


As Tab. 2 e 3 trazem a prevalência de focos por circuito e a prevalência de focos estratificada por tipo de exploração nos circuitos. $\mathrm{Na}$ Tab. 4, apresenta-se a prevalência de animais soropositivos.
$\mathrm{Na}$ Tab. 5, apresentam-se os resultados da análise univariada e na Tab. 6, o modelo final da regressão logística.

Tabela 2. Prevalência de focos de brucelose bovina na propriedade, segundo o circuito produtor, no Estado no Rio Grande do Sul

\begin{tabular}{|c|c|c|c|c|}
\hline \multirow{2}{*}{ Circuito produtor } & \multicolumn{2}{|c|}{ Propriedades } & \multirow{2}{*}{ Prevalência (\%) } & \multirow{2}{*}{ IC $(95 \%)$} \\
\hline & Testadas & Positivas & & \\
\hline 1- Sul & 294 & 9 & 3,06 & {$[1,40-5,73]$} \\
\hline 2- Fronteira Oeste & 298 & 23 & 7,71 & {$[4,95-11,35]$} \\
\hline 3- Missões Central & 318 & 18 & 5,66 & {$[3,38-8,79]$} \\
\hline 4- Norte & 302 & 2 & 0,66 & {$[0,08-2,37]$} \\
\hline 5- Serra & 300 & 2 & 0,66 & {$[0,08-2,38]$} \\
\hline 6- Metropolitana & 280 & 0 & 0,00 & {$[0,00-1,30]$} \\
\hline 7- Litoral Norte & 165 & 9 & 5,45 & {$[2,52-10,10]$} \\
\hline Total & 1.957 & 63 & 2,06 & {$[1,50-2,63]$} \\
\hline
\end{tabular}

IC: intervalo de confiança.

Tabela 3. Prevalência (Prev) de focos de brucelose bovina estratificada por tipo de exploração, segundo o circuito produtor, no Estado do Rio Grande do Sul

\begin{tabular}{|c|c|c|c|c|c|c|}
\hline \multirow{2}{*}{ Circuito produtor } & \multicolumn{2}{|c|}{ Corte } & \multicolumn{2}{|c|}{ Leite } & \multicolumn{2}{|c|}{ Misto } \\
\hline & Prev (\%) & IC (95\%) & Prev (\%) & IC (95\%) & Prev (\%) & IC (95\%) \\
\hline 1- Sul & 5,04 & {$[1,87-10,65]$} & 1,37 & {$[0,03-7,40]$} & 2,04 & {$[0,24-7,18]$} \\
\hline 2- Fronteira Oeste & 8,97 & {$[5,64-13,39]$} & 6,25 & {$[0,16-30,23]$} & 2,08 & {$[0,05-11,07]$} \\
\hline 3- Missões Central & 11,11 & {$[6,60-17,19]$} & 1,54 & {$[0,39-8,27]$} & 0,00 & {$[0,00-3,69]$} \\
\hline 4- Norte & 0,00 & {$[0,00-40,96]$} & 0,93 & {$[0,11-3,32]$} & 0,00 & {$[0,00-4,56]$} \\
\hline 5- Serra & 0,00 & {$[0,00-6,26]$} & 0,62 & {$[0,00-3,43]$} & 1,28 & {$[0,03-6,93]$} \\
\hline 6- Metropolitana & 0,00 & {$[0,00-7,39]$} & 0,00 & {$[0,00-3,84]$} & 0,00 & {$[0,00-2,86]$} \\
\hline 7- Litoral Norte & 21,05 & {$[9,55-37,32]$} & 1,78 & {$[0,04-9,55]$} & 0,00 & {$[0,00-5,51]$} \\
\hline
\end{tabular}

IC: intervalo de confiança.

Tabela 4. Prevalência de fêmeas bovinas sororreagentes para brucelose, segundo o circuito produtor, no Estado do Rio Grande do Sul

\begin{tabular}{|c|c|c|c|c|}
\hline \multirow{2}{*}{ Circuito produtor } & \multicolumn{2}{|c|}{ Animais } & \multirow{2}{*}{ Prevalência (\%) } & \multirow{2}{*}{ IC $(95 \%)$} \\
\hline & Testados & Positivos & & \\
\hline $1-\mathrm{Sul}$ & 2.396 & 25 & 0,95 & {$[0,00-1,97]$} \\
\hline 2- Fronteira Oeste & 3.626 & 27 & 1,04 & {$[0,40-1,68]$} \\
\hline 3- Missões Central & 3.736 & 34 & 2,12 & {$[0,41-3,83]$} \\
\hline 4- Norte & 1.991 & 6 & 0,66 & {$[0,00-1,81]$} \\
\hline 5- Serra & 1.919 & 2 & 0,05 & {$[0,00-0,13]$} \\
\hline 6- Metropolitana & 1.471 & 0 & 0,00 & {$[0,00-0,25]$} \\
\hline 7- Litoral Norte & 933 & 17 & 2,88 & {$[0,49-5,27]$} \\
\hline Total & 16.072 & 111 & 1,02 & {$[0,60-1,43]$} \\
\hline
\end{tabular}

IC: intervalo de confiança. 
Tabela 5. Resultados da análise univariada dos possíveis fatores de risco para brucelose bovina em rebanhos com atividade reprodutiva no Estado do Rio Grande do Sul

\begin{tabular}{lccc}
\hline Variável & Expostos/Casos & Expostos/Controles & $\mathrm{p}$ \\
\hline Rebanho extensivo & $52 / 60$ & $1.300 / 1.845$ & 0,006 \\
Exploração de corte & $52 / 63$ & $604 / 1.865$ & $<0,001$ \\
Exploração de leite & $7 / 63$ & $672 / 1.865$ & $<0,001$ \\
Exploração mista & $4 / 63$ & $589 / 1.865$ & $<0,001$ \\
Rebanho com mais de 19 fêmeas acima de 24 meses & $57 / 63$ & $907 / 1.894$ & $<0,001$ \\
Proporção de vacas em lactação $<0,33$ & $54 / 61$ & $897 / 1.813$ & $<0,001$ \\
Contato com ovinos/caprinos & $42 / 63$ & $577 / 1.888$ & $<0,001$ \\
Contato com equinos & $56 / 63$ & $962 / 1.893$ & $<0,001$ \\
Contato com suínos & $31 / 63$ & $1.164 / 1.894$ & 0,050 \\
Contato com aves & $45 / 63$ & $1.561 / 1.894$ & 0,025 \\
Contato com cão & $56 / 63$ & $1.680 / 1.893$ & 0,972 \\
Contato com gato & $43 / 63$ & $1.349 / 1.893$ & 0,604 \\
Contato com animais silvestres & $5 / 63$ & $96 / 1.890$ & $0,376 *$ \\
Contato com cervídeos & $3 / 63$ & $155 / 1.893$ & 0,326 \\
Contato com capivaras & $18 / 63$ & $177 / 1.893$ & $<0,001$ \\
Contato com outros animais silvestres & $5 / 63$ & $200 / 1.893$ & 0,503 \\
Utiliza inseminação artificial & $21 / 57$ & $654 / 1.765$ & 0,974 \\
Compra de animais para reprodução & $44 / 60$ & $825 / 1.796$ & $<0,001$ \\
Vende animais para reprodução & $17 / 57$ & $460 / 1.755$ & 0,542 \\
Apresenta histórico de aborto & $20 / 48$ & $334 / 1.632$ & $<0,001$ \\
Material de aborto sem destino ou destinado à & $32 / 45$ & $800 / 1.079$ & 0,650 \\
alimentação de porcos e cães & $2 / 59$ & $518 / 1.715$ & $<0,001$ \\
Abate animais na propriedade & $18 / 63$ & $285 / 1.822$ & 0,006 \\
Aluga pasto & $7 / 60$ & $201 / 1.825$ & 0,874 \\
Tem pasto em comum com outras propriedades & $30 / 61$ & $619 / 1.840$ & 0,012 \\
Tem áreas alagadiças & $30 / 63$ & $438 / 1.801$ & $<0,001$ \\
Tem piquete de parição & $50 / 63$ & $484 / 1.780$ & $<0,001$ \\
Vacina fêmeas entre 3 e 8 meses de idade com a B19 & $20 / 60$ & $816 / 1.784$ & 0,058 \\
Não tem assistência veterinária & & & \\
*Teste exato de Fisher & & & \\
\hline
\end{tabular}

Tabela 6. Modelo final da regressão logística múltipla de fatores de risco (odds ratio) para brucelose bovina em rebanhos com atividade reprodutiva no Estado do Rio Grande do Sul

\begin{tabular}{lccc}
\hline Variável & Odds ratio & IC $(95 \%)$ & $p$ \\
\hline Exploração de corte & 4,27 & {$[1,82-10,01]$} & $<0,001$ \\
Histórico de aborto & 3,27 & {$[1,71-6,25]$} & $<0,001$ \\
\hline
\end{tabular}

IC: intervalo de confiança.

Para o Estado, verificou-se prevalência de focos de brucelose de $2,1 \%$, porém com diferenças marcantes entre dois grupos de circuitos produtores (Tab. 2). Nos circuitos 1, 2, 3 e 7 a prevalência de focos variou de $3,1 \%$ a $7,7 \%$ e nos circuitos 4,5 e 6 , variou de $0 \%$ a $0,66 \%$ (Tab. 2).

Os circuitos 1, 2 e 3, localizados no sul do RS, detêm cerca de $65 \%$ do efetivo bovino, distribuído nas maiores propriedades do Estado, dedicadas principalmente à produção extensiva de carne (Santos et al., 2007). O circuito 7 representa o litoral norte e caracteriza-se por propriedades pequenas e com práticas de manejo muito simples, sem nenhum grau de tecnificação. Os circuitos 4, 5 e 6 encontram-se no norte do Estado e concentram o maior número de propriedades rurais, de rebanhos pequenos e destinados principalmente à pecuária de leite (Santos et al., 2007).

Os Boletins de Defesa Sanitária Animal dos anos de 1995 a 1998 (Boletim..., 1998-2000) mostraram prevalência de focos entre $0,42 \%$ e 1,4\% para os dados consolidados do Estado. 
Vale lembrar que esses dados não são oriundos de amostra planejada e o teste mais utilizado no período era a soroaglutinação rápida em placa, de sensibilidade muito baixa (Paulin e Ferreira Neto, 2003). Assim, considerando que a prevalência de focos verificada para todo Estado foi de 2,1\% (Tab. 2), é razoável supor que ela não se alterou muito desde meados dos anos 1990.

Em relação ao tipo de exploração, verificou-se que no circuito 3 há uma forte sugestão de maior prevalência de focos em rebanhos do tipo corte. No circuito 7, existe, de fato, maior concentração da infecção em rebanhos de corte (Tab. 3). Poester et al. (2002) já haviam sugerido que a brucelose bovina no RS estava mais concentrada nos rebanhos de corte.

Os estudos de prevalência da brucelose bovina, já realizados no RS, foram, na sua maioria, planejados para a obtenção da prevalência em animais. No presente estudo, a prevalência de animais positivos para todo o Estado foi de 1,0\%, com marcante diferença entre as duas regiões já mencionadas anteriormente (Tab. 4). Semelhante aos resultados de prevalência de focos, nos circuitos 1, 2, 3 e 7 a prevalência de animais foi mais elevada do que nos circuitos 4, 5 e 6 (Tab. 4).

Para todo o Estado, a prevalência de animais já havia sido calculada em 2,0\% em 1975 (Almeida et al., 1988) e 0,3\% em 1986 (Paulin e Ferreira Neto, 2003). O Boletim de Defesa Sanitária Animal mostrou que a frequência de bovinos soropositivos variou de $0,03 \%$ a $1,0 \%$ no período de 1995 a 1998 (Boletim..., 1998-2000). Groff (2007; SEAPPA-RS; comunicação pessoal) relatou que entre 1996 e 2007 foram testados 507.924 bovinos e bubalinos no RS, com $0,73 \%$ de positivos. Sabendo que a prevalência nos animais, verificada no presente estudo, foi de $1,0 \%$, conclui-se que a situação no Estado não se alterou significativamente desde a década de 1990.

Assim, os dados de literatura citados e os resultados do presente estudo indicam que a prevalência da brucelose no RS baixou de meados dos anos 1950 até meados de 1980 e, a partir daí, praticamente não se alterou. Essa diminuição da prevalência provavelmente foi resultado do melhor controle da doença pelos criadores de gado de leite (Boletim..., 19982000), localizados preferencialmente nos circuitos 4, 5 e 6 , os de mais baixa prevalência (Tab. 2 e 4). Adicionalmente, pode-se dizer que a brucelose está mais concentrada nas propriedades de corte nos circuitos 3 e 7 .

O estudo de prevalência mostrou que o Estado pode ser dividido em duas regiões distintas: uma abrangendo os circuitos 1, 2, 3 e 7 (Tab. 2 e 4) com prevalência elevada, a outra, representada pelos circuitos 4, 5 e 6 (Tab. 2 e 4), com prevalência baixa, notadamente no circuito 6 , onde não foram verificados animais positivos.

A região com prevalência maior deve obter cobertura vacinal eficiente com a B19, a fim de reduzir a prevalência com baixo custo. $\mathrm{Na}$ região norte, constituída pelos circuitos 4,5 e 6 , de prevalência muito baixa, o uso da vacina não traria melhoria da condição sanitária. Então, uma possibilidade seria a implementação de estratégias de erradicação nessa região, envolvendo a proibição da vacinação e a estruturação do sistema de vigilância para detecção e extinção dos focos residuais, conforme descrito por Paulin e Ferreira Neto (2003).

A detecção dos focos poderá ser feita de várias formas, tais como: pesquisa de anticorpos no leite, sorodiagnóstico de reprodutores descartados em abatedouro, sorodiagnóstico para movimentar animais de reprodução, estudos por amostragem, investigação de denúncia ou rumor, busca ativa nos produtores informais e investigação de casos de abortamento bovino e de brucelose humana. Adicionalmente, poderão ser investigadas as propriedades que mantêm relações comerciais com os focos. A reação seria sempre o saneamento do foco mediante rotina de testes indiretos com sacrifício de positivos. A decisão de adotar ou não duas estratégias no Estado dependerá da definição clara dessas estratégias tendo em vista a capacidade operacional do Serviço Veterinário Oficial.

$\mathrm{Na}$ análise univariada, a vacinação de bezerras com a B19 mostrou-se associada à condição de foco $(\mathrm{P}<0,001)$, o que é um paradoxo. $A$ explicação para esta associação é o fato de a vacinação ser recomendada pelo veterinário após a constatação da suspeita da doença na propriedade. Nos anos anteriores ao início do 
PNCEBT, o RS apresentava baixos índices de cobertura vacinal (Paulin e Ferreira Neto, 2003) e quando sinais da brucelose, como aborto, eram verificados na propriedade, o veterinário recomendava a vacinação com a B19. Assim, a vacinação foi uma consequência da presença da doença e não uma causa. Dessa forma, esta variável não foi oferecida à análise de regressão logística.

O modelo final da regressão logística indicou as variáveis exploração de corte e histórico de aborto como fatores de risco para a brucelose (Tab. 6).

Propriedades do tipo corte tiveram 3,27 vezes mais chances de serem focos de brucelose do que as do tipo leite e mistas juntas (Tab. 6). Poester et al. (2002) e Campero et al. (2003) já haviam sugerido essa associação. De fato, os dados da Tab. 3 mostram que a doença está mais concentrada nas propriedades de corte nos circuitos 3 e 7. Para os dados consolidados para o Estado, a mediana de fêmeas com idade igual ou superior a 24 meses foi de 57 para as propriedades de corte, 9 para as de leite e 5 para as mistas. Crawford et al. (1990) associaram tamanho de rebanho com ocorrência de brucelose, argumentando que tais unidades de produção praticam a reposição de animais com maior frequência, expondo o rebanho ao risco constante de introdução da doença. Assim, essa variável está indiretamente associada à maior frequência de reposição de animais, prática classicamente associada à condição de foco de brucelose. É importante ressaltar que apenas a introdução de reprodutores sem os devidos cuidados sanitários significa risco para a entrada da brucelose na propriedade.

O histórico de aborto é, na verdade, consequência da infecção brucélica, pois o abortamento é o principal sinal da doença na espécie bovina (Acha e Szyfres, 2001).

Recomenda-se: nos circuitos 1, 2, 3 e 7 concentrar esforços na obtenção, em todos os anos, de uma cobertura vacinal mínima de $80 \%$ de fêmeas entre três e oito meses de idade com a vacina B19; nos circuitos 4, 5 e 6 , considerar a possibilidade de implementar estratégias de erradicação. Essa iniciativa deverá envolver os Estados de Santa Catarina e Paraná, que também têm áreas de prevalência muito baixa. Essa seria a primeira grande área de erradicação da brucelose no Brasil e serviria como projeto piloto para todo o País.

\section{AGRADECIMENTOS}

À FAPESP, ao CNPq, à SEAPPA-RS e ao MAPA pelo apoio financeiro.

\section{REFERÊNCIAS BIBLIOGRÁFICAS}

ACHA, P.N.; SZYFRES, B. Zoonosis y enfermedades transmisibles comunes al hombre y a los animales: Bacterioses e micoses. 3.ed. Washington: OPAS, 2001. 416p.

ALMEIDA, G.L.G.; D`ALMEIDA, J.M. ; HORN, S.C. As doenças dos animais no Brasil: Histórico das primeiras observações. Bol. Def. Sanit. Anim, n.esp, 101p, 1988.

AVILA, A.F.D. Um modelo econométrico para carne bovina no Rio Grande do Sul, 1947-1970. 1973. 67f. Dissertação (Mestrado) Universidade Federal de Viçosa, Viçosa, MG.

BOLETIM DE DEFESA SANITÁRIA ANIMAL, v.28-30, n.1-4, 1998-2000.

BRASIL. Ministério de Agricultura, Pecuária e Abastecimento. Programa Nacional de Controle e Erradicação da Brucelose e da Tuberculose Animal (PNCEBT): Manual técnico. Brasília, 2006. $184 \mathrm{p}$.

CAMPERO, C.M.; MOORE, D.P.; ODEON, A.C. et al. Aetiology of bovine abortion in Argentina. Vet. Res. Commun., v.27, p.259-269, 2003.

CRAWFORD, R.P.; HUBER, J.D.; ADAMS, B.S. Epidemiology and surveillance. In: NIELSEN, K.; DUNCAN, J.R. (Ed.). Animal brucellosis. Boca Raton: CRC Press, 1990. p.131-151.

DEAN, A.G.; DEAN, J.A.; COLOMBIER, D. et al. Epi-Info, version 6: A word processing database and statistics program for epidemiology on microcomputers. Atlanta: CDC, 1994. 601p.

DOHOO, I.; MARTIN, W.; STRYHN, H. Veterinary epidemiologic research. Charlottetown, Canadá: Atlantic Veterinary College, 2003. 706p. 
DOMINGUES, O. Gado leiteiro para o Brasil: Gado europeu, gado indiano, gado bubalino. 9.ed. São Paulo: Nobel, 1982. 112p.

DUTRA, M.G.B. Evaluación cualitativa del riesgo de reintroducción de la fiebre aftosa en el Estado de Rio Grande do Sul. 2003. 246f. Tese (Doutorado) - Universidad de Murcia, Facultad de Veterinaria, Murcia, Espanha.

FLETCHER, R.H.; FLETCHER, S.W.; WAGNER, E.H. Clinical epidemiology: The essentials. 2.ed. Baltimore: Williams \& Wilkins, 1998. 246p.

IBGE. Censo agropecuário 2006: Resultados preliminares. Rio de Janeiro, 2006. Disponível em:

$<$ http://www.ibge.gov.br/home/estatistica/econo mia/agropecuaria/censoagro/2006/agropecuario.p df $>$. Acessado em: 11 jun. 2008.

PAULIN, L.M.; FERREIRA NETO, J.S. $O$ combate à brucelose bovina: Situação brasileira. Jaboticabal: Funep, 2003. 154p.
POESTER, F.P.; GONÇALVES, V.S.P.; LAGE, A.P. Brucellosis in Brazil. Vet. Microbiol., v.90, p.55-62, 2002.

RICHTER, H.V. Análise econômica do sistema produtivo e uso de nova tecnologia na exploração de gado de corte, Bagé, Rio Grande do Sul. 1971. 143f. Tese (Doutorado em Ciências Econômicas) - Faculdade de Ciências Econômicas, Universidade Federal do Rio grande do Sul, Porto Alegre, RS.

RIO GRANDE DO SUL. Governo do Estado do Rio Grande do Sul. Programa de combate à brucelose. 4.ed. Porto Alegre, 1961.

SANTOS, D.V.; DUTRA, M.G.B.; GROFF, F.H.S. Vacinação do rebanho bovídeo gaúcho contra a febre aftosa em janeiro de 2007. Hora Vet., v.27, n.159, p.13-16, 2007.

SILVA, A.B. O Zebu na Índia e no Brasil. Rio de Janeiro, 1947. p.58-59.

THRUSFIELD, M. Veterinary epidemiology. 3.ed. Oxford: Blackwell Science, 2007. 610p. 